\title{
LONG-TERM SHORELINE POSITION MONITORING AND PREDICTION, PEA ISLAND, NC
}

\author{
Elizabeth Sciaudone, North Carolina State University, ejsciaud@ncsu.edu \\ Liliana Velasquez Montoya, North Carolina State University, Ivelasq@ncsu.edu \\ Margery Overton, North Carolina State University, overton@ncsu.edu \\ Elizabeth Smyre, Dewberry, esmyre@dewberry.com
}

\section{INTRODUCTION}

Pea Island is a barrier island located on the Outer Banks of North Carolina, with Oregon Inlet to the north and Hatteras Island to the south. The northern end of the island is stabilized by a terminal groin, constructed between fall of 1989 and spring of 1991. Since 1990, approximately $10 \mathrm{~km}$ of shoreline downdrift (south) of the inlet has been monitored via aerial orthophotography every two months. In 2010, the monitoring area was expanded to approximately $21 \mathrm{~km}$ downdrift of the inlet (Figure 1). Shoreline position was historically drawn, and later digitized, as the visible wet-dry line on the orthophotos. These data, as well as available historical shoreline position information, were used to develop a robust shoreline position database to monitor changes and predict future shoreline behavior. Predictions of shoreline positions are of interest to coastal managers and state transportation authorities, whose obligation to maintain a transportation corridor along the barrier island necessitates careful planning. The aim of the present study is to evaluate the accuracy of shoreline forecasts made based on linear regression with a prediction interval, and their applicability to coastal planning and management.

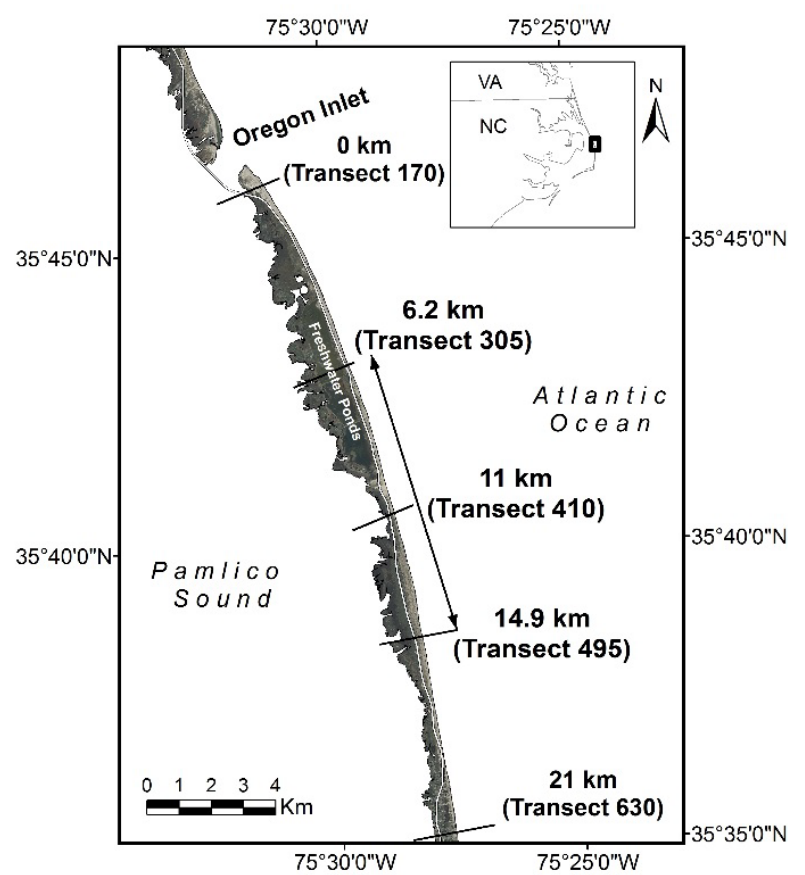

Figure 1 - Pea Island location map. The area between transects 305 and 495 was the focus of this study.
LINEAR REGRESSION WITH PREDICTION INTERVAL Typically, linear regression on shoreline position is conducted using a system of shore-perpendicular transects, with shoreline position measurements referenced to a baseline. The linear regression equation is developed with the slope of the regression line corresponding to the shoreline change rate. This method has been shown to reduce uncertainty when compared with endpoint erosion rate and shoreline forecasts (e.g., Douglas and Crowell, 2000, Honeycutt et al., 2001).

Overton et al. (2004) used a linear regression shoreline forecast along with the prediction interval associated with that forecast to evaluate influence of a structure on barrier island shoreline change. Since 2010, the authors have used the prediction interval in presenting the range of future shoreline positions for the state transportation authority's planning horizons of 2030 and 2060.

The prediction interval is expressed as:

$\hat{y}_{h} \pm t_{(\alpha / 2, n-2)} \times \sqrt{\operatorname{MSE}\left(1+\frac{1}{n}+\frac{\left(x_{h}-\bar{x}\right)^{2}}{\sum\left(x_{i}-\bar{x}\right)^{2}}\right)}$

Where $\hat{y}_{h}$ is the predicted value of the response when the predictor is $X_{h}, t_{(\alpha / 2, n-2)}$ is the t-multiplier for the desired interval, and the term

$\sqrt{\operatorname{MSE}\left(1+\frac{1}{n}+\frac{\left(x_{h}-\bar{x}\right)^{2}}{\sum\left(x_{i}-\bar{x}\right)^{2}}\right)}$ is the standard error

of the prediction. For this study, the implementation of the prediction interval in Matlab is employed.

\section{EVALUATION OF PREDICTION INTERVAL}

As part of the present research, the predictive success of the prediction interval methodology is examined, and the dependence on the number of shoreline positions assessed. Areas found to be influenced by the terminal groin (Overton et al. 2004) and a 2014 beach nourishment project were excluded from the analysis. Shorelines associated with formation and closure of an ephemeral inlet within the study area were also excluded.

An $8.7 \mathrm{~km}$ stretch of barrier island shoreline with 191 transects spaced at $45.7 \mathrm{~m}$ was examined in this study (Figure 1). Four date ranges were used to forecast the 
December 2016 shoreline position with 95\% confidence. The percentage of observed shoreline positions falling within the $95 \%$ prediction interval range are considered the indicator of the success of the forecast. Note that the variability of the shoreline positions affects the width of the prediction interval. On average, the prediction interval tends to decrease in width with the addition of more data and the proximity to the time of the prediction, however, in some cases, the variability of the data causes an increase in the prediction interval width at specific transects.

Figure 2 shows an example of the linear regression and prediction interval at Transect 410 near the middle of the study area. The width of the prediction interval at this transect at the forecast date (December 2016) decreased from approximately $25 \mathrm{~m}$ as of the December 1993 shoreline forecast, to $21 \mathrm{~m}$ as of the December 2011 forecast.

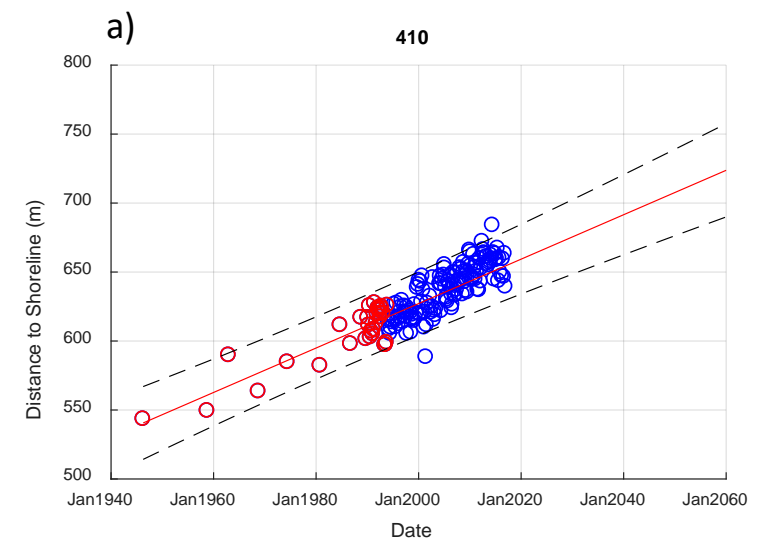

b)

410

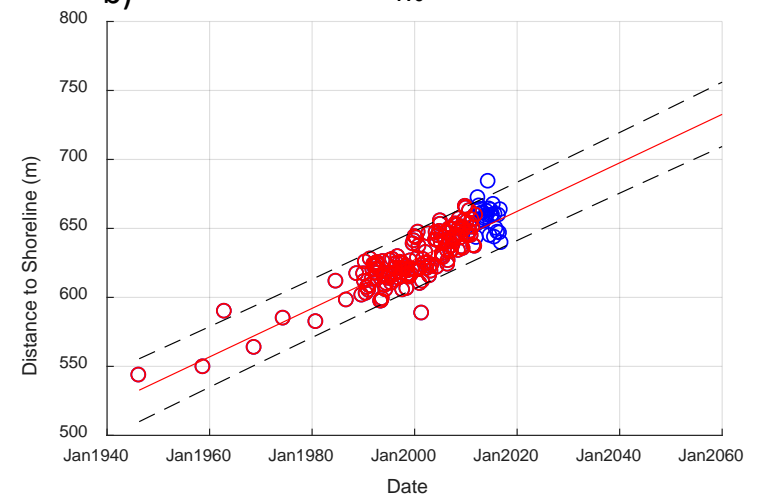

Figure 2 - Linear regression of shoreline position at Transect 410, a) using data from April 1946 to Dec. 1993, and b) using data from April 1946 to Dec. 2011. Red circles indicate data used in the regression, blue circles indicate shoreline positions measured at later dates. The solid red line is the linear regression line and the dashed black lines delineate the $95 \%$ prediction interval.
Results in Table 1 show the performance of the various shoreline forecasts for the December 2016 measured shoreline. The highest percentage of shoreline positions falling within the prediction interval is found for the earliest forecast (1946-1993 data), however, this is due to the larger prediction interval range (reflecting the greater uncertainty of this forecast when compared with subsequent ones).

As the prediction interval range decreases, fewer measured positions are within the interval for the 19462000 forecast, however, as more shorelines are added to the dataset, the percentage of measured positions within the prediction interval increases. With $80 \%$ or more of the observed shoreline positions falling within the prediction interval for all forecasts, the method is considered to be reasonable for planning and management applications. Future work to be presented will include further evaluation of prediction interval and examination of seasonality.

Table 1 - Predictive success of 95\% prediction interval for shoreline forecasting using varying date ranges.

\begin{tabular}{|c|c|c|c|}
\hline $\begin{array}{c}\text { Date Range } \\
\text { used to } \\
\text { predict } \\
\text { position }\end{array}$ & $\begin{array}{c}\text { No. of } \\
\text { shorelines } \\
\text { available }\end{array}$ & $\begin{array}{c}\text { Average } \\
\text { width of } \\
\text { prediction } \\
\text { interval } \\
\text { (m) }\end{array}$ & $\begin{array}{c}\text { \% of measured } \\
\text { Dec. 2016 } \\
\text { shoreline } \\
\text { positions within } \\
\text { prediction } \\
\text { interval }\end{array}$ \\
\hline $\begin{array}{c}\text { April 1946- } \\
\text { December } \\
1993\end{array}$ & $\sim 34$ & \pm 50 & $90 \%$ \\
\hline $\begin{array}{c}\text { April 1946- } \\
\text { December } \\
2000\end{array}$ & $\sim 76$ & \pm 39 & $80 \%$ \\
\hline $\begin{array}{c}\text { April 1946- } \\
\text { December } \\
2006\end{array}$ & $\sim 111$ & \pm 36 & $81 \%$ \\
\hline $\begin{array}{c}\text { April 1946- } \\
\text { December } \\
2011\end{array}$ & $\sim 145$ & \pm 32 & $85 \%$ \\
\hline
\end{tabular}

\section{REFERENCES}

Douglas and Crowell (2000): Long-term shoreline position prediction and error propagation, J. Coastal Res. 16(1) pp. 145-152.

Honeycutt, Crowell, and Douglas (2001): Shorelineposition forecasting: Impact of storms, rate-calculation methodologies, and temporal scales, J. Coastal Res.17(3) pp. 721-730.

Overton, Fisher, and Dolan (2004): Predicting Shoreline Change on a Manipulated Shoreline. Coastal Engineering 2004: pp. 2462-2470. 